\title{
Benefits and drawbacks of electronic health record systems
}

This article was published in the following Dove Press journal:

Risk Management and Healthcare Policy

II May 20II

Number of times this article has been viewed

\author{
Nir Menachemi' \\ Taleah H Collum ${ }^{2}$ \\ 'Department of Health Care \\ Organization and Policy, University \\ of Alabama at Birmingham, \\ Birmingham, AL, USA; ${ }^{2}$ Department \\ of Health Services Administration, \\ University of Alabama at Birmingham, \\ Birmingham, AL, USA
}

Abstract: The Health Information Technology for Economic and Clinical Health (HITECH) Act of 2009 that was signed into law as part of the "stimulus package" represents the largest US initiative to date that is designed to encourage widespread use of electronic health records (EHRs). In light of the changes anticipated from this policy initiative, the purpose of this paper is to review and summarize the literature on the benefits and drawbacks of EHR systems. Much of the literature has focused on key EHR functionalities, including clinical decision support systems, computerized order entry systems, and health information exchange. Our paper describes the potential benefits of EHRs that include clinical outcomes (eg, improved quality, reduced medical errors), organizational outcomes (eg, financial and operational benefits), and societal outcomes (eg, improved ability to conduct research, improved population health, reduced costs). Despite these benefits, studies in the literature highlight drawbacks associated with EHRs, which include the high upfront acquisition costs, ongoing maintenance costs, and disruptions to workflows that contribute to temporary losses in productivity that are the result of learning a new system. Moreover, EHRs are associated with potential perceived privacy concerns among patients, which are further addressed legislatively in the HITECH Act. Overall, experts and policymakers believe that significant benefits to patients and society can be realized when EHRs are widely adopted and used in a "meaningful" way.

Keywords: EHR, health information technology, HITECH, computerized order entry, health information exchange

\section{Introduction}

Over the past decade, virtually every major industry invested heavily in computerization. Relative to a decade ago, today more Americans buy airline tickets and check in to flights online, purchase goods on the Web, and even earn degrees online in such disciplines as nursing, ${ }^{1}$ law, ${ }^{2}$ and business, ${ }^{3}$ among others. Yet, despite these advances in our society, the majority of patients are given handwritten medication prescriptions, and very few patients are able to email their physician ${ }^{4}$ or even schedule an appointment to see a provider without speaking to a live receptionist. ${ }^{5}$

Electronic health record (EHR) systems have the potential to transform the health care system from a mostly paper-based industry to one that utilizes clinical and other pieces of information to assist providers in delivering higher quality of care to their patients. The Health Information Technology for Economic and Clinical Health (HITECH) Act of 2009, which is part of the American Recovery and Reinvestment Act (ARRA) (aka "stimulus package"), was signed into law with an explicit purpose of incentivizing providers (eg, hospitals and physicians) to adopt EHR systems.
Correspondence: Nir Menachemi UAB School of Public Health, 1530 3rd

Ave, S Birmingham, AL 35294, USA

$\mathrm{Tel}+\mathrm{I} 2059347$ 192

Fax + I 2059343347

Email nmenachemi@uab.edu 
However, given that a bare-bone EHR system provides only partial benefits to patients and society, ${ }^{6}$ the HITECH Act requires that providers adopt EHRs and utilize them in a "meaningful" way, which includes using certain EHR functionalities associated with error reduction and cost containment. How exactly do EHRs improve care? And what is the current evidence that certain EHR "meaningful use" functionalities will translate into benefits? Answering these questions is the purpose of this paper. Stated explicitly, the purpose of this study is to review the literature on the impacts of EHR. Impacts include both benefits and drawbacks, and, as such, we discuss the advantages and disadvantages that have been identified by researchers and other experts. Overall, we expect that any reader interested in understanding the current state of the knowledge base with regard to EHR benefits will find this paper useful.

\section{Why we need EHRs}

EHRs are defined as "a longitudinal electronic record of patient health information generated by one or more encounters in any care delivery setting. Included in this information are patient demographics, progress notes, problems, medications, vital signs, past medical history, immunizations, laboratory data, and radiology reports". ${ }^{7}$ Some of the basic benefits associated with EHRs include being able to easily access computerized records and the elimination of poor penmanship, which has historically plagued the medical chart. ${ }^{8,9}$ EHR systems can include many potential capabilities, but three particular functionalities hold great promise in improving the quality of care and reducing costs at the health care system level: clinical decision support (CDS) tools, computerized physician order entry (CPOE) systems, and health information exchange (HIE). These and other EHR capabilities are requirements of the "meaningful use" criteria set forth in the HITECH Act of 2009. ${ }^{10}$

A CDS system is one that assists the provider in making decisions with regard to patient care. Some functionalities of a CDS system include providing the latest information about a drug, cross-referencing a patient allergy to a medication, and alerts for drug interactions and other potential patient issues that are flagged by the computer. With the continuous growth of medical knowledge, each of these functionalities provides a means for care to be delivered in a much safer and more efficient manner. As more and more CDS systems are used, one can expect certain medical errors to be averted and that, overall, the patient will receive more efficient and safe care. ${ }^{11}$

CPOE systems allow providers to enter orders (eg, for drugs, laboratory tests, radiology, physical therapy) into a computer rather than doing so on paper. Computerization of this process eliminates potentially dangerous medical errors caused by poor penmanship of physicians. It also makes the ordering process more efficient because nursing and pharmacy staffs do not need to seek clarification or to solicit missing information from illegible or incomplete orders. Previous studies suggest that serious medication errors can be reduced by as much as $55 \%$ when a CPOE system is used alone, ${ }^{12}$ and by $83 \%$ when coupled with a CDS system that creates alerts based on what the physician orders. ${ }^{13}$ Using a CPOE system, especially when it is linked to a CDS, can result in improved efficiency and effectiveness of care.

Once health data are available electronically to providers, EHRs facilitate the sharing of patient information through HIE. HIE is the process of sharing patient-level electronic health information between different organizations ${ }^{14}$ and can create many efficiencies in the delivery of health care. ${ }^{15}$ By allowing for the secure and potentially real-time sharing of patient information, HIE can reduce costly redundant tests that are ordered because one provider does not have access to the clinical information stored at another provider's location. Patients typically have data stored in a variety of locations where they receive care. This can include their primary care physician's office, as well as other physician specialists, one or more pharmacies, and other locations, such as hospitals and emergency departments. Over a lifetime, much data accumulates at a variety of different places, all of which are stored in silos. Historically, providers rely on faxing or mailing each other pertinent information, which makes it difficult to access in "real time" when and where it is needed. HIE facilitates the exchange of this information via EHRs, which can result in much more cost-effective and higher-quality care.

In the following section, we describe the literature that has examined the effect of EHRs on various clinical and organizational outcomes. A large proportion of the literature has focused on one or more computerized capabilities of EHRs, including CDS, CPOE, and HIE. Many of these studies have been discussed in previously published literature reviews, ${ }^{16-20}$ so we further summarize them here.

\section{Advantages of EHRs}

Researchers have examined the benefits of EHRs by considering clinical, organizational, and societal outcomes. Clinical outcomes include improvements in the quality of care, a reduction in medical errors, and other improvements in patient-level measures that describe the appropriateness of care. Organizational outcomes, on the other hand, have 
included such items as financial and operational performance, as well as satisfaction among patients and clinicians who use EHRs. Lastly, societal outcomes include being better able to conduct research and achieving improved population health.

\section{EHRs and clinical outcomes}

Many clinical outcomes that have been a focus of EHR studies relate to quality of care and patient safety. Quality of care has been defined as "doing the right thing at the right time in the right way to the right person and having the best possible results", ${ }^{21}$ and patient safety has been defined as "avoiding injuries to patients from the care that is intended to help them". ${ }^{11}$ Quality of care includes six dimensions, ${ }^{11}$ but most EHR research has focused on the following three: patient safety, effectiveness, and efficiency. In the following paragraphs we summarize some of the studies that examine how EHRs or various related components impact these three quality dimensions. More research is needed on the other three components: patient centeredness, timeliness, and equitable access.

EHRs, especially those with CDS tools, have been empirically linked to an increased adherence to evidencebased clinical guidelines and effective care. Despite the best intention of providers, various factors may result in patient encounters that do not adhere to best practice guidelines. Some reasons for this nonadherence include i) clinicians not knowing the guidelines, ii) clinicians not realizing that a guideline applies to a given patient, and iii) lack of time during the patient visit. EHR systems try to overcome these issues, and researchers have focused on preventive services, including vaccine administration, to examine how EHRs can improve adherence rates. For example, researchers found that computerized physician reminders increased the use of influenza and pneumococcal vaccinations from practically $0 \%$ to $35 \%$ and $50 \%$, respectively, for hospitalized patients. ${ }^{22}$ A similar study, but in the outpatient setting, found that computerized reminders were associated with improved influenza and pneumococcal vaccination rates among rheumatology patients taking immunosuppressant medications. ${ }^{23}$ Specifically, influenza vaccinations increased from $47 \%$ to $65 \%$ of patients, and pneumococcal vaccinations increased from $19 \%$ to $41 \%$ of patients. Other studies on vaccination rates found comparable results that computerized reminders can improve adherence to immunization guidelines. ${ }^{24,25}$

From the societal public health perspective, adhering to these guidelines keeps individuals healthy and lowers the risk of disease outbreaks in communities. Researchers have also focused on other preventive services and on how EHRs can improve various outcomes and make care more effective. Kucher et $\mathrm{al}^{26}$ hypothesized that computerized alerts, as part of a CPOE system with CDS, directed at physicians may increase the use of prophylactic care for hospitalized patients at high risk for deep vein thrombosis. They found a 19\% increase in the use of anticoagulation prophylaxis when using computer alerts, and this translated into a $41 \%$ reduced risk of deep vein thrombosis or pulmonary embolism at 90 days after discharge. Willson et $\mathrm{a}^{27}$ found a significant association between computerized reminders and pressure ulcer prevention in hospitalized patients. They found a 5\% decrease in the development of pressure ulcers 6 months after the implementation of computerized reminders that targeted hospital nurses. Other similar studies found comparable results. Rossi and Every, ${ }^{28}$ for example, found that computerized reminders as part of a CDS have been linked to an $11.3 \%$ increase in appropriate hypertension treatment in a primary care setting. Other studies in the outpatient setting have also found that an EHR and its components significantly increase adherence to protocol-based or recommended care..$^{29,30}$

Although researchers have found CDS tools to be beneficial in most situations, many medical conditions do not have scientifically based guidelines for providers to follow, thus reducing the usefulness and effectiveness of these tools in many clinical situations. More scientific-based guidelines need to be developed in order to maximize the benefits associated with CDS. Similar to a focus on adherence to guidelines, researchers have also found an association between EHRs and efficiency in health care delivery. Efficiency refers to the avoidance of wasting resources, including supplies, equipment, ideas, and energy. ${ }^{11}$ One such form of waste involves redundant diagnostic testing. Performing redundant tests is costly and may lead to more false-positive results, which will then lead to even more costs. ${ }^{31}$ Evidence indicates that there is a significant negative (eg, desirable) association between redundant diagnostic testing and the use of an EHR and/or its components. For example, Nies et $\mathrm{al}^{32}$ examined the affects of a CDS on the redundancy of blood tests in a cardiovascular surgery department. They found that point-of-care computerized reminders of previous blood tests significantly reduced the proportion of unnecessarily repeated tests. In the outpatient setting, Tierney et $\mathrm{al}^{33}$ found a $14.3 \%$ decrease in the number of diagnostic tests ordered per visit and a $12.9 \%$ decrease in diagnostic test costs per visit when using an EHR with CDS and CPOE components. Other, unrelated studies found an $18 \%$ decrease in tests ordered for medical visits in the emergency department, ${ }^{34}$ a $27 \%$ decrease in 
redundant laboratory tests of antiepileptic medication levels in hospitalized patients, ${ }^{35}$ and a $24 \%$ reduction in redundant laboratory tests in a hospital. ${ }^{36}$

Studies focusing on patient safety have frequently examined the effect of EHR components on medical or medication errors. In a widely cited study, experts found that a CPOE system was associated with a $55 \%$ reduction in serious medication errors in the hospital setting. ${ }^{12}$ A follow-up study by the same team found that by adding a CDS system to a CPOE system, medication errors can be reduced by as much as $86 \% .{ }^{13}$ A similar, more recent study in the outpatient setting found that computerization resulted in an error rate reduction from $18.2 \%$ to $8.2 \% .{ }^{37}$ Other studies have concluded that the number of appropriate medication orders involving dosing levels or dosing frequency can be increased with the use of a computerized system. ${ }^{38}$ Specifically, in one study, the use of a CDS yielded a $32 \%$ decrease in the number of days that antibiotics were prescribed outside the recommended dosage range and a 59\% decrease in the need for pharmacist intervention to correct a drug dose. ${ }^{39}$ On the other hand, a few studies have found an association between the use of CPOE and increased medical errors. These increases generally occur due to poorly designed system interfaces, lack of end-user training, ${ }^{40}$ or lack of systems integration. ${ }^{41}$ Factors such as dense pull-down menus and text entries in inappropriate areas of an EHR can have negative consequences for patients. ${ }^{40}$ Specifically, one study found that the use of a CPOE was associated with 22 types of medication error risks. ${ }^{41}$

Many of the studies described have focused on clinical outcomes at the patient level. Such studies have been conducted in a clinical setting, frequently by employing a randomized trial research design. An additional body of literature has examined, observationally, whether hospitals that have adopted EHR or other computerized capabilities perform better than their counterparts that have not. For example, Menachemi et $\mathrm{al}^{42}$ found that Florida hospitals with greater investments in EHR technologies had more desirable rates on a variety of commonly used quality indicators. In a similar study of hospitals, researchers found that computerized records and order entry were associated with lower mortality rates, and CDS was associated with fewer complications. ${ }^{43}$ Additionally, the same study found that computerized test results, order entry, and CDS were all associated with lower costs. However, despite the results discussed here, other researchers have found only small positive effects from EHR adoption $^{44,45}$ or mixed results. ${ }^{46}$

\section{EHRs and organizational and societal outcomes \\ Organizational outcomes}

Studies examining organizational outcomes have focused on EHR use in both the inpatient and outpatient settings. Such outcomes have frequently included increased revenue, averted costs, and other benefits that are less tangible, such as improved legal and regulatory compliance, improved ability to conduct research, and increased job/career satisfaction among physicians. Increased revenue comes from multiple sources, including improved charge capture/decrease in billing errors, improved cash flow, and enhanced revenue. Several authors have asserted that EHRs assist providers in accurately capturing patient charges in a timely manner. ${ }^{47,48}$ With an EHR system, many billing errors or inaccurate coding may be eliminated, which will potentially increase a provider's cash flow and enhance revenue. ${ }^{18,49,50}$ Reductions to outstanding days in accounts receivable and lost or disallowable charges can potentially lead to improved cash flow. ${ }^{50}$ In addition, EHR reminders to providers and patients about routine health visits can increase patient visits and therefore enhance revenue. ${ }^{49}$

Many averted costs associated with EHRs are the result of efficiencies created by having patient information electronically available. Some of these include increased utilization of tests, reduced staff resources devoted to patient management, reduced costs relating to supplies needed to maintain paper files, decreased transcription costs, and the costs relating to chart pulls. The use of EHRs can reduce the redundant use of tests or the need to mail hard copies of test results to different providers. ${ }^{35,51}$ By making patient information more readily available, EHRs reduce costs related to chart pulls ${ }^{52}$ as well as supplies needed to maintain paper charts. ${ }^{53}$ Studies have also shown that having an EHR as opposed to a paper file can result in reduced transcription costs through pointof-care documentation and other structured documentation procedures. ${ }^{50}$ One author found a significant decrease in staff resources dedicated to anemia management for hemodialysis patients when a CDS was used for medication dosing. ${ }^{54}$

Other, less tangible benefits have been associated with EHR use. In a study conducted by Bhattacherjee et al, ${ }^{55}$ Florida hospitals with a greater adoption of health information technology had higher operational performance, as measured by outcomes of Joint Commission on Accreditation of Healthcare Organizations (JCAHO) site visits. It has also been pointed out that EHRs can facilitate improved legal and regulatory compliance in terms of increased security of 
data and enhanced patient confidentiality through controlled and auditable provider access. ${ }^{50}$ In addition, researchers in Massachusetts have found that physicians using an EHR had fewer paid malpractice claims. ${ }^{56}$ Specifically, they found that $6.1 \%$ of physicians with an EHR had a history of paid malpractice claims compared with $10.8 \%$ of physicians without EHRs. This reduction is potentially the result of increased communication among caregivers, increased legibility and completeness of patient records, and increased adherence to clinical guidelines.

\section{Societal benefits}

Another less tangible benefit associated with EHRs is an improved ability to conduct research. Having patient data stored electronically increases the availability of data, which may lead to more quantitative analyses to identify evidencebased best practices more easily. ${ }^{57}$ Moreover, public health researchers are actively using electronic clinical data that are aggregated across populations to produce research that is beneficial to society. The availability of clinical data is limited, but as providers continue to implement EHRs, this pool of data will grow. By combining aggregated clinical data with other sources, such as over-the-counter medication purchases and school absenteeism rates, public health organizations and researchers will be able to better monitor disease outbreaks and improve surveillance of potential biological threats. ${ }^{58}$

Researchers have also found an association between EHR use and physician satisfaction with their current practice, ${ }^{59}$ as well as their career satisfaction. ${ }^{60}$ According to many studies, physician satisfaction should be a priority in health care organizations, because it is associated with better quality of care, better prescribing behaviors, and increased retention in medical practices, particularly those in underserved areas. ${ }^{61,62}$

To balance the generally positive findings of the aforementioned studies, Chaudhry et $\mathrm{al}^{16}$ noted that a large proportion of the studies that found benefits from EHR were conducted in a select number of academic medical centers. This raises the question about whether or not many of the benefits identified can be generalized to other settings of care that do not have similar financial and human resources nor a decades-long commitment to health information technology. More research on the varying types and degrees of benefits associated with EHR is warranted, especially in community settings such as physician practices and nonacademic hospital settings.

\section{Potential disadvantages of EHRs}

Despite the growing literature on benefits of various EHR functionalities, some authors have identified potential disadvantages associated with this technology. These include financial issues, changes in workflow, temporary loss of productivity associated with EHR adoption, privacy and security concerns, and several unintended consequences.

Financial issues, including adoption and implementation costs, ongoing maintenance costs, loss of revenue associated with temporary loss of productivity, and declines in revenue, present a disincentive for hospitals and physicians to adopt and implement an EHR. EHR adoption and implementation costs include purchasing and installing hardware and software, converting paper charts to electronic ones, and training end-users. Many studies have documented these costs in both the inpatient and outpatient settings. ${ }^{47,50}$ In a 2002 study conducted in a 280-bed acute care hospital, the projected total cost for a 7-year-long EHR installation project was approximately US\$19 million. ${ }^{47}$ In the outpatient setting, early researchers estimated an average initial cost of US\$50,000-US\$70,000 per physician for a three-physician office. ${ }^{50}$ However, as EHR technologies have become more commonplace over the past decade, the initial cost of systems has come down dramatically. One industry group estimated hardware, software, services, and telecommunications cost of approximately US\$14,000 per physician in the initial year of implementation for a sixphysician practice and US\$19,000 per physician with three or fewer physicians. ${ }^{63}$ Similarly, a recent study estimates initial costs of software, training, and installation of US\$22,038 and hardware costs of US\$13,000 per full-time-equivalent (FTE) provider in a solo or small-group primary care practice. ${ }^{64}$ Lastly, another study estimated costs during the first 60 days of launch of US\$162,047 (or US\$32,409 per physician) for a five-physician practice to implement an EHR system. ${ }^{65}$

The maintenance cost of an EHR can also be costly. Hardware must be replaced and software must be upgraded on a regular basis. In addition, providers must have ongoing training and support for the end-users of an EHR. According to one study conducted on 14 solo or small-group primary care practices, estimated ongoing EHR maintenance costs averaged US\$8412 per FTE provider per year. A total of $91 \%$ of this cost was related to hardware replacement, vendor software maintenance and support fees, and payments for information systems staff or external contractors. ${ }^{64}$ Other estimates of ongoing maintenance costs for the first year after implementation were about US\$17,100 per physician in a medical group of five. ${ }^{65}$ 
The costs of EHR adoption, implementation, and ongoing maintenance are compounded by the fact that many financial benefits of an EHR generally do not accrue to the provider (who is required to make the upfront investment) but rather to the third-party payers in the form of errors averted and improved efficiencies, which translate into reduced claims payments. This misalignment of incentives for health care organizations, along with the high upfront costs, creates a barrier to adoption and implementation of an EHR, especially for smaller practices. In fact, physicians frequently cite upfront costs and ongoing maintenance costs as the largest barriers to adoption and implementation of an EHR. ${ }^{66}$

Another disadvantage of an EHR is disruption of workflows for medical staff and providers, which result in temporary losses in productivity. This loss of productivity stems from end-users learning the new system and may potentially lead to losses in revenue. One study involving several internal medicine clinics estimated a productivity loss of $20 \%$ in the first month, $10 \%$ in the second month, and 5\% in the third month, with productivity subsequently returning to its original levels. ${ }^{52}$ In that study, the loss in productivity resulted in lost revenue of US\$11,200 per provider in the first year. In a study of solo and small-group primary care practices of one to six FTE providers, revenue losses from reduced visits during the initial stages of an EHR averaged approximately US\$7500 per FTE provider. This depended on whether physicians worked longer hours during this stage or reduced patient visits. ${ }^{64}$ Lastly, researchers have estimated that EHR end-users spent 134.2 hours on implementation activities associated with getting and learning a new system. These hours spent on nonclinical responsibilities had an estimated cost of US\$10,325 per physician. ${ }^{65}$

Other declines in revenue are possible following EHR implementation. Because EHRs are often associated with fewer redundancies, fewer errors, and shorter lengths of stay, it is conceivable that a given provider may avert certain billable transactions that, although superfluous, may have generated reimbursements from third-party payers, especially in a fee-for-service payment system. Although reimbursement rates may differ for each organization, these declines could be offset by increased revenue that is generated as a result of efficiencies achieved with the help of an EHR system. ${ }^{64}$

Another potential drawback of EHRs is the risk of patient privacy violations, which is an increasing concern for patients due to the increasing amount of health information exchanged electronically. ${ }^{67,68}$ To relieve some of these concerns, policymakers have taken measures to ensure safety and privacy of patient data. For example, recent legislation has imposed regulations specifically relating to the electronic exchange of health information that strengthen existing Health Insurance Portability and Accountability Act privacy and security policies. ${ }^{69}$ Although few electronic data are $100 \%$ secure, the rigorous requirements set forth by the new legislation make it much more difficult for electronic data to be accessed inappropriately. For example, all EHR systems are required to have an audit function that allows system operators to identify each individual who accessed every aspect of a given medical record. Many hospitals and physicians are implementing strict, no tolerance penalties for employees who access files inappropriately. For example, a hospital in Arizona terminated several employees after they inappropriately accessed the records of victims who were hospitalized after the January 2011 shooting involving a US Congresswoman. ${ }^{70}$ Although privacy will likely continue to be a concern for patients, many steps are being taken by policymakers and individual organizations to ensure that EHRs comply with the strict laws and regulations intended to ensure the privacy of clinical information.

EHRs may cause several unintended consequences, such as increased medical errors, negative emotions, changes in power structure, and overdependence on technology. ${ }^{40}$ As mentioned previously, researchers have found an association between the use of CPOE and increased medical errors due to poorly designed system interfaces or lack of end-user training. Additionally, end-users of an EHR may experience strong emotional responses as they struggle to adapt to new technology and disruptions in their workflow. Changes in the power structure of an organization may also occur due to the implementation of an EHR. For example, a physician may lose his or her autonomy in making patient decisions because an EHR blocks the ordering of certain tests or medications. Overdependence on technology may also become an issue for providers as they become more reliant upon it. Organizations should ensure that basic medical care can still be provided in the absence of technology, especially in times when the downtime of the system may be critical. Although there are many unintended consequences of EHRs, when balancing the advantages and disadvantages of these systems, they are beneficial, especially at the society level.

\section{Conclusion}

In this paper we discussed several advantages and disadvantages associated with an EHR adoption. Many of the benefits accrue to patients and society overall. For these benefits to be realized, the US Government has embarked 
on an ambitious journey to transition a maximum number of providers toward EHR adoption and "meaningful use". Without ubiquitous use of EHR technologies, experts believe that many efficiencies in the US health care system cannot be realized. ${ }^{15}$ The financial incentives built into the HITECH Act are designed to defray some of the costs associated with EHR adoption, especially for smaller organizations where these expenses serve as a major barrier. The financial incentives in HITECH, which are made available through the Medicare and Medicaid programs, are also an attempt to correct some of the misalignment of incentives associated with EHR as discussed previously, especially because the US Government, through the Medicare and Medicaid programs, is the largest insurer in the country.

Incentives made available to physicians through the HITECH Act differ among Medicaid and Medicare physicians. ${ }^{71}$ Medicaid offers more generous incentives than Medicare and has less stringent requirements for the first year. Physicians with more than $30 \%$ of their patients paying with Medicaid are eligible for up to US\$63,750 in incentives over a 6 -year period. They can begin earning these incentives as they adopt, implement, or upgrade an EHR. The last year to begin participation in the Medicaid incentive program is 2016, and physicians do not need to begin proving "meaningful use" until the second year of their program participation. On the other hand, physicians accepting more Medicare patients are eligible for up to US\$44,000 over a 5 -year period as long as they can meet the "meaningful use" criteria starting the first year. Physicians not meeting the "meaningful use" criteria by 2015 will be assessed for penalties in the form of reduced Medicare reimbursements. Physicians are allowed to participate in either the Medicaid or Medicare incentive program, but not both. Those who are eligible are expected to participate in the Medicaid program, because its benefits are more generous. Hospitals are also eligible for incentives under the HITECH Act. The amount of the incentives they receive depends on a number of factors, but the base amount to each hospital that complies with the meaningful use criteria will be more than US\$2 million. Both physician and hospital incentives are structured so that those immediately achieving meaningful use of an EHR will receive larger payments.

Providers are also expected to face technological and logistical obstacles on their quest to achieve meaningful use of EHRs. ${ }^{72}$ To help combat the technological problems faced by providers, the federal government, through the HITECH Act, has committed approximately US\$650 million for the establishment of a network of up to 70 regional health information technology extension centers. The primary purpose of these organizations is to offer advice to physicians on which information technology systems they should purchase and assistance on how to become meaningful users of EHRs. To address some of the logistical problems associated with EHRs, the federal government has entrusted US\$560 million under the HITECH Act to state governments for the development of infrastructure to facilitate the exchange of health information.

Nationwide implementation of EHRs is a necessary, although not sufficient, part in transforming the US health care system for the better. EHR adoption must be considered one of many approaches that diversify our focus on quality improvement and cost reduction. The current major legislative and political support for EHRs represents the greatest investment in health information technologies in US history. Over time, providers and researchers will be eager to quantify the returns that are expected from these investments.

\section{Disclosure}

The authors report no conflicts of interest in this work.

\section{References}

1. Mancuso-Murphy J. Distance education in nursing: an integrated review of online nursing students' experiences with technology-delivered instruction. J Nurs Educ. 2007;46(6):252-260.

2. Lopez T, Clinton S. Will law schools go the distance? An annotated bibliography on distance education in law. Law Library Journal. 1999; 91(4):655-691.

3. Haugen S, Becker D, Erffmeyer R. Standards for determining the quality of online MBA education: a survey of accredited programmes. International Journal of Services and Standards. 2004;1(2):193-205.

4. Menachemi N, Prickett C, Brooks R. The use of physician-patient email in Florida 2005-2008: a follow-up examination of adoption and "best practice" adherence. J Med Internet Res. 2011;12(1):e23.

5. Galewitz P. Medical practices increasingly allow online appointments. US A Today. January 3, 2011.

6. Menachemi N, Ford EW, Beitsch LM, Brooks RG. Incomplete EHR adoption: late uptake of patient safety and cost control functions. $\mathrm{Am} \mathrm{J}$ Med Qual. 2007;22(5):319-326.

7. HIMSS. EHR definition. http://www.himss.org/ASP/topics_ehr.asp. Accessed January 31, 2011.

8. Winslow EH, Nestor VA, Davidoff SK, et al. Legibility and completeness of physicians' handwritten medication orders. Heart Lung. 1997;26(2):158-164.

9. Rodriguez-Vera FJ, Marin Y, Sanchez A, et al. Illegible handwriting in medical records. JR Soc Med. 2002;95(11):545-546.

10. Blumenthal D, Tavenner $M$. The "meaningful use" regulation for electronic health records. $N$ Engl J Med. 2010;363(6):501-504.

11. IOM. Crossing the quality chasm: a new health system for the 21 st century. Washington, DC: Institute of Medicine; 2001.

12. Bates DW, Leape LL, Cullen DJ, et al. Effect of computerized physician order entry and a team intervention on prevention of serious medication errors. JAMA. 1998;280(15):1311-1316.

13. Bates DW, Teich JM, Lee J, et al. The impact of computerized physician order entry on medication error prevention. J Am Med Inform Assoc. 1999;6(4):313-321. 
14. The National Alliance for Health Information Technology. Report to the Office of the National Coordinator for Health Information Technology on Defining Key Health Information Technology Terms. http://healthit. hhs.gov/portal/server.pt/community/healthit_hhs_gov_reports/1239. Accessed April 18, 2011.

15. Walker J, Pan E, Johnston D, et al. The value of health care information exchange and interoperability. Health Aff (Millwood). 2005; Suppl:W5-10-W15-18.

16. Chaudhry B, Wang J, Wu S, et al. Systematic review: impact of health information technology on quality, efficiency, and costs of medical care. Ann Intern Med. 2006;144(10):742-752.

17. Menachemi N, Brooks RG. Reviewing the benefits of electronic health records and associated patient safety technologies. J Med Syst. 2006; 30(3):159-168.

18. Erstad T. Analyzing computer based patient records: a review of literature. J Healthc Inf Manag. 2003;17(4):51-57.

19. Kaushal R, Shojania KG, Bates DW. Effects of computerized physician order entry and clinical decision support systems on medication safety: a systematic review. Arch Intern Med. 2003;163(12):1409-1416.

20. Goldzweig CL, Towfigh A, Maglione M, Shekelle PG. Costs and benefits of health information technology: new trends from the literature. Health Aff (Millwood). 2009;28(2):w282-w293.

21. AHRQ. National Healthcare Quality Report. AHRQ Publication No. 05-0013ed. Rockville, MD: Agency for Healthcare Research and Quality; 2004.

22. Dexter PR, Perkins S, Overhage JM, et al. A computerized reminder system to increase the use of preventive care for hospitalized patients. N Engl J Med. 2001;345(13):965-970.

23. Ledwich LJ, Harrington TM, Ayoub WT, et al. Improved influenza and pneumococcal vaccination in rheumatology patients taking immunosuppressants using an electronic health record best practice alert. Arthritis Rheum. 2009;61(11):1505-1510.

24. McDonald CJ, Hui SL, Tierney WM. Effects of computer reminders for influenza vaccination on morbidity during influenza epidemics. MD Comput. 1992;9(5):304-312.

25. Tierney WM, Hui SL, McDonald CJ. Delayed feedback of physician performance versus immediate reminders to perform preventive care. Effects on physician compliance. Med Care. 1986;24(8):659-666.

26. Kucher N, Koo S, Quiroz R, et al. Electronic alerts to prevent venous thromboembolism among hospitalized patients. $N$ Engl J Med. 2005;352(10):969-977.

27. Willson D, Ashton C, Wingate N, et al. Computerized support of pressure ulcer prevention and treatment protocols. Proc Annu Symp Comput Appl Med Care. 1995:646-650.

28. Rossi RA, Every NR. A computerized intervention to decrease the use of calcium channel blockers in hypertension. J Gen Intern Med. 1997;12(11):672-678.

29. McDonald CJ, Hui SL, Smith DM, et al. Reminders to physicians from an introspective computer medical record. A two-year randomized trial. Ann Intern Med. 1984;100(1):130-138.

30. Demakis JG, Beauchamp C, Cull WL, et al. Improving residents' compliance with standards of ambulatory care: results from the VA Cooperative Study on Computerized Reminders. JAMA. 2000;284(11): 1411-1416.

31. Bates DW, Goldman L, Lee TH. Contaminant blood cultures and resource utilization. The true consequences of false-positive results. JAMA. 1991;265(3):365-369.

32. Nies J, Colombet I, Zapletal E, et al. Effects of automated alerts on unnecessarily repeated serology tests in a cardiovascular surgery department: a time series analysis. BMC Health Serv Res. 2010;10:70.

33. Tierney WM, Miller ME, McDonald CJ. The effect on test ordering of informing physicians of the charges for outpatient diagnostic tests. N Engl J Med. 1990;322(21):1499-1504.

34. Wilson GA, McDonald CJ, McCabe GP Jr. The effect of immediate access to a computerized medical record on physician test ordering: a controlled clinical trial in the emergency room. Am J Public Health. 1982;72(7):698-702.
35. Chen P, Tanasijevic MJ, Schoenenberger RA, et al. A computer-based intervention for improving the appropriateness of antiepileptic drug level monitoring. Am J Clin Pathol. 2003;119(3):432-438.

36. Bates DW, Kuperman GJ, Rittenberg E, et al. A randomized trial of a computer-based intervention to reduce utilization of redundant laboratory tests. Am J Med. 1999;106(2):144-150.

37. Devine EB, Hansen RN, Wilson-Norton JL, et al. The impact of computerized provider order entry on medication errors in a multispecialty group practice. J Am Med Inform Assoc. 2010;17(1):78-84.

38. Chertow GM, Lee J, Kuperman GJ, et al. Guided medication dosing for inpatients with renal insufficiency. JAMA. 2001;286(22):2839-2844.

39. Mullett CJ, Evans RS, Christenson JC, Dean JM. Development and impact of a computerized pediatric antiinfective decision support program. Pediatrics. 2001;108(4):E75.

40. Campbell EM, Sittig DF, Ash JS, et al. Types of unintended consequences related to computerized provider order entry. J Am Med Inform Assoc. 2006;13(5):547-556.

41. Koppel R, Metlay JP, Cohen A, et al. Role of computerized physician order entry systems in facilitating medication errors. JAMA. 2005; 293(10):1197-1203.

42. Menachemi N, Chukmaitov A, Saunders C, Brooks R. Hospital quality of care: does information technology matter? The relationship between information technology adoption and quality of care. Health Care Manage Rev. 2008;33(1):51-59.

43. Amarasingham R, Plantinga L, Diener-West M, et al. Clinical information technologies and inpatient outcomes: a multiple hospital study. Arch Intern Med. 2009;169(2):108-114.

44. DesRoches CM, Campbell EG, Vogeli C, et al. Electronic health records' limited successes suggest more targeted uses. Health Aff (Millwood). 2010;29(4):639-646.

45. McCullough JS, Casey M, Moscovice I, Prasad S. The effect of health information technology on quality in US hospitals. Health Aff (Millwood). 2010;29(4):647-654.

46. Jones SS, Adams JL, Schneider EC, et al. Electronic health record adoption and quality improvement in US hospitals. Am J Manag Care. 2010;16(12 Suppl HIT):SP64-SP71.

47. Schmitt KF, Wofford DA. Financial analysis projects clear returns from electronic medical records. Healthc Financ Manage. 2002;56(1): 52-57.

48. Williams B. How to do an ROI (return on investment). Healthc Inform. 1990;7(2):30-32.

49. Mildon J, Cohen T. Drivers in the electronic medical records market. Health Manag Technol. 2001;22:14-18.

50. Agrawal A. Return on investment analysis for a computer-based patient record in the outpatient clinic setting. J Assoc Acad Minor Phys. 2002; 13(3):61-65.

51. Tierney WM, Miller ME, Overhage JM, McDonald CJ. Physician inpatient order writing on microcomputer workstations. Effects on resource utilization. JAMA. 1993;269(3):379-383.

52. Wang SJ, Middleton B, Prosser LA, et al. A cost-benefit analysis of electronic medical records in primary care. Am J Med. 2003;114(5):397-403.

53. Ewing T, Cusick D. Knowing what to measure. Healthcare Financial Management. 2004;58(6):60-63.

54. Miskulin DC, Weiner DE, Tighiouart H, et al. Computerized decision support for EPO dosing in hemodialysis patients. Am J Kidney Dis. 2009;54(6):1081-1088.

55. Bhattacherjee A, Hikmet N, Menachemi N, et al. The differential performance effects of healthcare information technology adoption. Information Systems Management. 2007;24(1):5-14.

56. Virapongse A, Bates DW, Shi P, et al. Electronic health records and malpractice claims in office practice. Arch Intern Med. 2008;168(21): 2362-2367.

57. Aspden P. Patient Safety Achieving a New Standard for Care. Washington, D.C.: National Academies Press; 2004.

58. Kukafka R, Ancker JS, Chan C, et al. Redesigning electronic health record systems to support public health. J Biomed Inform. 2007;40(4): $398-409$. 
59. Menachemi N, Powers TL, Brooks RG. The role of information technology usage in physician practice satisfaction. Health Care Manage Rev. 2009;34(4):364-371.

60. Elder KT, Wiltshire JC, Rooks RN, et al. Health information technology and physician career satisfaction. Perspect Health Inf Manag. 2010;7:1d.

61. Linzer M, Konrad TR, Douglas J, et al. Managed care, time pressure, and physician job satisfaction: results from the physician worklife study. J Gen Intern Med. 2000;15(7):441-450.

62. Pathman DE, Williams ES, Konrad TR. Rural physician satisfaction: its sources and relationship to retention. J Rural Health. 1996;12(5): 366-377.

63. CDW. CDW Healthcare Physician Practice EHR Price Tag. Vernon Hills, IL; 2010.

64. Miller RH, West C, Brown TM, et al. The value of electronic health records in solo or small group practices. Health Aff (Millwood). 2005; 24(5):1127-1137.

65. Fleming NS, Culler SD, McCorkle R, et al. The financial and nonfinancial costs of implementing electronic health records in primary care practices. Health Aff (Millwood). 2011;30(3):481-489.
66. Menachemi N. Barriers to ambulatory EHR: who are 'imminent adopters' and how do they differ from other physicians? Inform Prim Care. 2006;14(2):101-108.

67. Zurita L, Nohr C. Patient opinion: EHR assessment from the users perspective. Stud Health Technol Inform. 2004;107(2):1333-1336.

68. Westin AF. Public attitudes toward electronic health records. Privacy and American Business. 2005;12(2):1-6.

69. Parver C. How the American Recovery and Reinvestment Act of 2009 Changed HIPAA's privacy requirements. CCH Health Care Compliance Letter. July 28, 2009:4-7.

70. Innes S. 3 UMC workers fired for invading records. Arizona Daily Star. January 13, 2011.

71. Bruen BK, Ku L, Burke MF, Buntin MB. More than four in five officebased physicians could qualify for federal electronic health record incentives. Health Aff (Millwood). 30(3):472-480.

72. Blumenthal D. Stimulating the adoption of health information technology. N Engl J Med. 2009;360(15):1477-1479.
Risk Management and Healthcare Policy

\section{Publish your work in this journal}

Risk Management and Healthcare Policy is an international, peerreviewed, open access journal focusing on all aspects of public health, policy, and preventative measures to promote good health and improve morbidity and mortality in the population. The journal welcomes submitted papers covering original research, basic science, clinical \& epidemio-

\section{Dovepress}

logical studies, reviews and evaluations, guidelines, expert opinion and commentary, case reports and extended reports. The manuscript management system is completely online and includes a very quick and fair peerreview system, which is all easy to use. Visit http://www.dovepress.com/ testimonials.php to read real quotes from published authors. 